\title{
NARRATIVAS DE PSICÓLOGAS A PARTIR DA LEI MARIA DA PENHA
}

\author{
Marilda Castelar ${ }^{1}$, Amanda Torquatro ${ }^{1}$ e Verena Souza Souto ${ }^{1}$ \\ ${ }^{1}$ Escola Bahiana de Medicina e Saúde Pública, Brasil, marildacastelar@bahiana.edu.br \\ amanda.torquatro@hotmail.com, verena.souto@gmail.com
}

\begin{abstract}
Resumo. Este trabalho objetiva discutir as narrativas de psicólogas na política pública para mulheres em situação de violência a partir da Lei Maria da Penha. Método: Pesquisa qualitativa exploratória. Foram realizadas sete entrevistas com psicólogas, gravadas em áudio, transcritas e posteriormente fez-se uma análise de conteúdo. Resultados: Foram encontradas profissionais de Psicologia inseridas em todos os equipamentos especializados com algum conhecimento da Lei 11.340/06 e das políticas públicas para as mulheres. Entretanto, apresentam dificuldades no manejo da rede e no conhecimento teórico e metodológico na operacionalização de suas práticas profissionais e apenas uma participa do movimento de mulheres. Conclusões: Apesar da importância das psicólogas no acolhimento e acompanhamento à mulher em situação de violência, é necessário aperfeiçoar o conhecimento dessas profissionais sobre a Lei 11.340/06 e sobre as políticas públicas voltadas para mulheres. Além de aprimorar a formação das psicólogas frente à violência contra mulheres.
\end{abstract}

Palavras-chave: Mulher; Violência; Psicologia; Lei Maria da Penha

\section{NARRATIVES OF PSYCHOLOGISTS FROM THE MARIA DA PENHA LAW}

\begin{abstract}
The work objective discuss the narratives of psychologists in public policy for women in situations of violence based on the Maria da Penha Law. Methodology: Qualitative exploratory research. Were conducted seven interviews with psychologists, audio-recorded, transcribed, and subsequently an analysis was made of the content. Results: were found professional psychology entered all the specialized equipment with some knowledge of the Law 11.340/06 and of public policies for women. However present difficulties in the management of the network and in the knowledge of the theoretical and methodological operationalization of their professional practices, and only one participates in the women's movement. Conclusion: Despite the importance of the psychologist in the reception and accompaniment to women in situations of violence, it is still necessary to improve the knowledge of these professionals about the Law 11.340/06 and on the public policies for women. In addition to improving the training of psychologists about violence against women.
\end{abstract}

Keywords: Woman. Violence; Psychology; Maria da Penha Law.

\section{INTRODUÇÃO}

A violência contra as mulheres é símbolo de uma das principais formas de violação dos seus direitos humanos, atingindo-as em seus direitos fundamentais, como à vida, à saúde e à integridade física, moral e psicológica (Brasil, 2011). É uma realidade que perpassa gerações e tal modalidade de violência é um fenômeno social que acontece nas relações humanas em que há conflitos de interesse e dominação. A violência doméstica é tida como um tipo de violência de gênero, que ocorre dentro do lar, definida como qualquer ato de agressão física, sexual ou emocional perpetrado por um indivíduo com quem se tenha ou se teve um relacionamento (Ferreira at al, 2016). A violência contra a mulher perpassa 
gerações e passou a ser mais discutida em sociedade, na mídia e nas redes sociais. De acordo com o Atlas da Violência 2019 há um crescimento dos feminicídios nos últimos anos, especialmente por arma de fogo a partir de 2015 (IPEA, 2019).

O que é perceptível é a discussão do assunto para que todas as mulheres compreendam seus direitos e assim cobrem a efetividade da Lei, bem como a consistência das políticas públicas, para que estas venham a auxiliá-las em situação de violência doméstica. Tais políticas baseiam-se em um paradigma de "rede" e de "transversalidade de gênero". Promove-se a criação de uma "rede de enfrentamento" à violência contra a mulher, o que inclui instituições e serviços governamentais e não governamentais, bem como a comunidade. Além disso, abrange a "rede de atendimento" constituída de serviços assistenciais e ações setoriais que devem ser articuladas e integradas com enfoque em saúde, segurança pública, justiça, assistência social e educação.

Nesse sentido, a elaboração de uma lei específica para a violência de gênero foi resultado do trabalho e mobilização dos movimentos de mulheres, potencializado pela criação da Secretaria Especial de Políticas para as Mulheres da Presidência da República. Com a Lei 11.340/2006, um dos objetivos foi caracterizar a violência de gênero como violação dos direitos humanos e elaborar uma lei que garantisse proteção e procedimentos humanizados para as vítimas (Mascarenhas, 2013).

Com o apoio do movimento feminista do Brasil e de organizações não governamentais. A Lei 11.340/06 é considerada um marco na história da luta das mulheres no Brasil; esta lei criou "mecanismos para coibir e prevenir a violência doméstica e familiar contra a mulher, para Prevenir, Punir e Erradicar". A lei também criou os "Juizados de Violência Doméstica e Familiar contra a Mulher". Igualmente, há de se destacar que o artigo $5^{\circ}$ desta lei define violência doméstica e familiar como ação ou omissão que tem por base o gênero, vindo tal violência a causar os mais variados danos (Brasil, 2006). Diante desse cenário as autoridades sentiram a necessidade da criação de uma nova Lei, aprovada em 2015, a Lei do Feminicídio (lei 13.104/15), a qual incute o homicídio de uma mulher pela condição de gênero.

Cabe ressaltar que com a Lei Maria da Penha, foi possível também a criação e aperfeiçoamento das políticas públicas de enfrentamento à violência contra as mulheres englobando as diferentes modalidades pelas quais a violência se expressa, além da qualificação de equipes multiprofissionais e a inserção de psicólogas têm sido cada vez 
mais demandadas. Nesse sentido, se faz necessário estudar as práticas locais das Psicólogas em serviços e Programas de Atenção às Mulheres em Situação de Violência para compreender como estas realizam e compreendem suas atividades.

\section{METODOLOGIA}

O presente trabalho trata-se de uma pesquisa qualitativa de caráter exploratório e descritivo. As interlocutoras da pesquisa foram psicólogas que atuam nos equipamentos da Rede de Atendimento à Mulher em situação de Violência, existentes em Salvador e em algumas localidades do interior da Bahia. Foram contemplados na presente pesquisa, a saber: Centro de Referência a Atenção à Mulher; Serviço Especializado de Acolhimento a Mulheres em situação de Violência Doméstica do Campo, da Floresta e das Águas; Juizado Especializado; Defensoria Pública; Ministério Público.

Foram utilizados como critérios de inclusão psicólogas que atuam no acolhimento e acompanhamento a mulheres em situação de violência nos equipamentos que operacionalizam as políticas para as mulheres, que aceitaram participar do presente estudo e vieram a apresentar em seus relatos aspectos relevantes ao recorte da pesquisa. Foram excluídas psicólogas que não atuavam nos equipamentos que operacionalizam as políticas públicas e que não se sentiram à vontade com a gravação em áudio, assinando o TCLE. Este estudo aprovado pelo Comitê de Ética CAAE: 60401816.6.0000.5544. Todas as participantes assinaram o termo de consentimento livre e esclarecido (TCLE).

As informações foram obtidas através de entrevistas realizadas individualmente, em local adequado escolhido pelas participantes, estas foram gravadas em áudio e transcritas pelas pesquisadoras e encontram-se no banco de dados do grupo de pesquisa. Essas entrevistas dizem respeito a seis psicólogas/os, com idade média de 35 anos. Apenas uma se autodeclarou branca, três pardas e duas negras. Quanto à religião, três disseram não possuir, uma se declarou católica, uma evangélica e uma candomblecista. Gênero: cinco são do gênero mulher e um homem. Média de tempo após graduação foi de 9 anos.

Os dados das entrevistas foram analisados segundo a Análise de Conteúdo, associada à temática e a análise de conteúdo de Bauer (2002). As identificações das unidades de análise foram realizadas com seis entrevistas transcritas, conferidas, provenientes de uma leitura flutuante e focada, marcada pelo conteúdo das falas. As entrevistas foram agrupadas por semelhança de conteúdo, advinda das falas manifestadas e analisadas após as leituras 
flutuantes, emergindo duas categorias com aspectos relevantes do conhecimento relacionados a Lei Maria da Penha e das políticas públicas específicas para o campo no caso do presente artigo trataremos apenas do Conhecimento da Lei, em que foram incluídas afirmativas ou negativas da resposta direta à pergunta: se conheciam aspectos da descrição da lei que as entrevistadas citaram para justificar o seu conhecimento ou desconhecimento da lei;

\section{RESULTADOS E DISCUSSÃO}

Nesta seção foram analisadas as narrativas relacionadas à percepção das psicólogas que trabalham em alguns dos equipamentos de assistência prestada às mulheres em situação de violência, de Salvador e região a partir de apenas uma das categorias de análise citadas acima.

\subsection{Conhecimento da Lei Maria da Penha}

Com a Lei no 11.340/2006, caracterizando a violência doméstica como uma forma de violação dos direitos humanos, impondo penas mais duras aos agressores e maior proteção judicial e policial para as vítimas (Vieira, Hasse, 2017). Na perspectiva de entendimento do que é a Lei Maria da Penha e qual a sua função, a entrevistada E-3 relata seu trabalho de transmissão de informações contidas na lei para as mulheres que atende baseada em aspectos fundamentais a exemplo dos tipos de violência que são tipificados como possíveis de acontecer no âmbito doméstico.

Por conta do trabalho eu tive que estudar também a lei, mas eu acabo me atendo muito mais às tipificações de violência na minha prática e também a forma com que a mulher pode chegar à delegacia, por exemplo, e pedir para registrar uma queixa né, então basicamente eu conheço a lei, mas eu trabalho basicamente com a explicação dos 5 tipos , a física, a patrimonial, a sexual, a moral ou verbal e a psicológica (...)(E-3)

Além de possuir o conhecimento sobre a Lei, E-3 relata o aprofundamento do estudo mediante a necessidade encontrada na sua atuação profissional, revelando como compartilha seus conhecimentos com as mulheres que apresentam essas demandas, explicando o que é a violência doméstica, a Lei e até como proceder com relação aos mecanismos a fim de assegurar a integridade dessas mulheres. A postura da entrevistada aqui explicitada evidencia uma necessidade latente de as psicólogas, enquanto profissionais, conhecerem a Lei Maria da Penha de forma profunda, já que, ao levar ao conhecimento da mulher em situação de violência a política que rege seus direitos, a 
mesma poderá agir em consonância com aquilo que a Lei determina, que configura a prática realizada por E3.

Tal conhecimento sobre a norma legal, bem como a devida orientação à mulher pode vir a salvar vidas, tendo em vista que poderá proporcionar à mulher que tome as devidas providências para se proteger de futuras agressões. Isto se relaciona a outro aspecto que ficou evidenciado nos relatos: a repercussão da Lei do Feminicídio, em que se entende que existe mais incidência da morte de mulheres quando a agressão envolve violência doméstica e familiar, e/ou quando evidencia menosprezo ou discriminação à condição de mulher, caracterizando crime por razões de condição do gênero da vítima. (IPEIA, 2019).

Para viabilizar a mudança no Código Penal, foi tipificado o feminicídio como "circunstância qualificadora", assim, esse tipo de crime contra mulheres passou a ser considerado no rol dos crimes hediondos (Brasil, 2015). Isto requer uma mudança de cultura que ainda não foi processada na sociedade. A entrevistada abaixo comenta sobre esse fato:

Lei do Feminicídio que é muito pouco conhecida também é recente e traz aspectos muito importantes. Então eu acho que a Lei Maria da Penha é uma lei fundamental e eu a considero bem elaborada. (E1)

Ratificando a fala da E-1, a literatura suscita que o país compartilha as limitações quanto à informação pública, acessível e confiável sobre o tema, especialmente na fase criminal e judiciária. Não há dúvidas de que, em breve, poderá ser possível contar com algumas informações estatísticas de inquéritos policiais tipificados como feminicídios, em função da aprovação recente que tipifica como crimes hediondos os homicídios de mulheres por motivação de gênero (Brasil, 2016).

Como ilustrado abaixo pela E-4, foi abordada também a discussão de gênero pautada dentro do Sistema Conselhos de Psicologia, abordando as normativas técnicas e os posicionamentos políticos sobre o tema, debatendo e problematizando essas contribuições, como no caso a Lei para o fazer profissional das psicólogas, uma vez que já existe toda uma estrutura nas redes para assistir esse público (CFP, 2013).

Uma lei bem completa, mas foi produzida pensando numa realidade que é complexa, multifacetada, então ela atenta não só a questões judiciais, como questões de acolhimento ao próprio agressor, tudo isso é previsto na lei, mas quando você coloca isso em prática, trazer isso para realidade, você como entender que algumas coisas ali, precisam ser melhoradas, então, por exemplo, quando você pensa, em medida protetiva de urgência, é algo que é necessário, mas quando a mulher recebe a medida 
protetiva de urgência, quem vai garantir que essa medida funcione? Então, aí a gente precisa pensar em outras questões para dar conta disso. (E-4)

Perante a complexidade que permeia a violência contra as mulheres, destacam-se os profissionais que atuam na atenção a esta população, no sentido de que estes necessitam ampliar seu olhar sobre o problema, voltando-se para além do tratamento dos traumas físicos e da denúncia dos agressores. É fundamental a elaboração e implantação de ações de enfrentamento articuladas intersetorialmente e interdisciplinarmente. Dessa maneira, além da queixa e do trato das questões físicas, é possível agir na mudança do comportamento agressivo do ofensor e na promoção da igualdade de gênero (Madureira at al, 2014).

Além disso, aparecem questões direcionadas ao agressor, como exemplifica a fala abaixo:

A Lei... é falha, deveria se ter uma ressocialização aquele homem foi detido, mas ele teria que ter um processo uma equipe que até que ele saia e responda, fizesse entender, porque ele está ali e eu não sei se isso de fato acontece (...) então de fato eu acho que a lei é extremamente falha, não é só pegar prender, você fazer uma entrevista, não, tem que ter um acompanhamento e isso não tem. Lá existe agora (...) grupos que os próprios psicólogos voluntários estão fazendo, grupos de homens e grupos de mulheres. (E-5).

Para E-5 a compreensão dos aspectos subjetivos que permeiam situações de violência doméstica na perspectiva dos homens que perpetra a violência, com vista a incluí-los como protagonistas no processo de enfrentar a violência. Com isto, pode-se fornecer elementos fundamentais a ser utilizados no desenvolvimento de políticas e estratégias preventivas, a ser realizadas nas redes locais para atendimento e assistência, através da implementação de ações educativas com grupos de homens que cometeram violência, cuja discussão pode ser promovida no campo da violência doméstica, resolução de conflitos, e promoção de uma cultura da paz e da igualdade de gênero (Madureira, at al 2014).

Os estudos demonstram que mulheres em situação de violência doméstica costumam procurar inicialmente as chamadas redes sociais, sendo estas compostas por amigos/as, genitores e irmãos/irmãs etc. Inclusive, as publicações nacionais e internacionais sinalizaram crescimento de estudos relacionados às referidas redes, o que demonstra o seu reconhecimento e importância como mecanismo para o enfrentamento da violência contra a mulher (Krenkel, Moré, 2017). 
Contudo, salienta-se a necessidade de melhorias principalmente da continuidade nas redes intersetoriais, que são os equipamentos que operacionalizam as políticas para as mulheres. Estudos que enfocam na qualidade da assistência prestada, nas respostas às demandas das mulheres e a possibilidade de articulação que existem, avaliam que há um despreparo por parte profissional para trabalhar com a temática da violência, quanto na concepção intersetorial o que faria perdurar um histórico de práticas de preconceito e discriminação, principalmente nos setores de justiça e segurança pública, que reforçam estereótipos de gênero e dificultam a oferta efetiva de cuidados (Vieira, Hasse, 2017).

\section{CONSIDERAÇÕES FINAIS}

Com esse estudo foi possível compreender a necessidade e a importância das narrativas para desvelar aspectos da compreensão e da atuação das psicólogas, principalmente as que atuam nos equipamentos que operacionalizam as políticas para as mulheres. Sendo oferecido o acolhimento das demandas e a busca de caminhos para proporcionar uma qualidade de vida melhor às mulheres em situação de violência, trazendo dignidade e a permitindo usufruir dos seus direitos.

Ainda é necessário aperfeiçoar o conhecimento dessas profissionais sobre a Lei Maria da Penha e das políticas públicas voltadas para mulheres. Percebe-se que possuem algum conhecimento sobre, mas há, ainda, uma inconsistência no manejo dessas políticas e da Lei na prática e no processo de dirigir a mulher em situação de violência dentro da rede, já que se depara com muitas questões que dificultam a estabilidade e efetividade da rede, uma vez que a mesma já passa por um processo de indagação sobre a eficiência por uma questão de medo das mulheres que pensam e/ou vão atrás desses serviços, já que os índices de violência a esse público está cada vez maior.

Mesmo com as divulgações nos meios de comunicação sobre a violência doméstica, as campanhas educativas acerca das políticas voltadas para as mulheres ainda são insuficientes, o que faz com que muitas profissionais da área não conheçam de forma superficial as demandas dessa população e, como consequência, não aconteça um atendimento e suporte de excelência, como se é esperado quando se trata dessa temática.

Faz-se indispensável o aprimoramento dos conhecimentos referentes à formação das psicólogas sobre essa temática por inúmeras razões, dentre elas por ser uma graduação majoritariamente cursada por mulheres, por ser uma questão de saúde pública, por ser um 
tema presente na conjuntura atual da sociedade e por faltar discussões desse assunto nos âmbitos acadêmicos. Não se pode deixar de ressaltar, ainda, que existe a demanda de profissionais qualificados para ocupar esses lugares (redes).

\section{REFERÊNCIAS}

Bauer, M. W. \& Gaskell, G. (2002). Pesquisa e Qualitativa com Texto, Imagem e Som: Manual Prático, Editora Vozes, Cap.8 p.189.

Brasil. (2006). Lei Maria da Penha (Lei 11.340/06).

Brasil. (2011). Política Nacional de Enfrentamento à violência contra as Mulheres. Brasília: Secretaria de Políticas para as Mulheres - Presidência da República.

Brasil. (2015). Lei do Feminicídio (Lei 13.104/15).

Conselho Federal de Psicologia. (2013). Documento De Referência Para Atuação De Psicólogas (Os) Em Serviços De Atenção À Mulher Em Situação De Violência. Brasília: CFP.

Conselho Regional de Psicologia. (2013). Gênero na psicologia: articulações e discussões. Brasília: CFP.

Ferreira, R. M., Vasconcelos, T. B., Filho, R. E. M. \& Macena, R. H. M. (2016). Características de saúde de mulheres em situação de violência doméstica abrigadas em uma unidade de proteção estadual. Ciência \& Saúde Coletiva, 21(12), 3937-3946.

Krenkel, S., \& Moré, C. L. O. O. (2017). Violência contra a Mulher, Casas-Abrigo e Redes Sociais: Revisão Sistemática da Literatura. Psicologia: Ciência e Profissão, 37(3), 770-783.

Instituto de Pesquisa Econômica Aplicada. (2019). Atlas da Violência. (2019). Brasília: Rio de Janeiro: São Paulo: Instituto de Pesquisa Econômica Aplicada; Fórum Brasileiro de Segurança Pública.

Lhullier, Louise A. (org.) (2013). Quem É A Psicóloga Brasileira? Mulher, Psicologia e Trabalho. Brasília: CFP.

Machado, L. Z. (2016). Feminismos brasileiros nas relações com o Estado. Contextos e incertezas. Cadernos Pagu, (47), e16471.

Madureira, A. B., Raimondo, M. L., Ferraz M. I. R., Marcovicz G. V., Labronici L. M. \& Mantovani, M. F. (2014). Homens autores de violência contra mulheres detidos. Escola Anna Nery Revista de Enfermagem 18(4).

Mascarenhas, M. (2013). Violência cometida por pessoa conhecida. Revista Ciência \& Saúde Coletiva, 18(3), $691-700$

Santos, C. M. (2015). Curto-circuito, falta de linha ou na linha? Redes de enfrentamento à violência contra mulheres em São Paulo. Revista Estudos Feministas, 23(2), 577-600.

Vieira, E. M.; Hasse, M. (2017). Percepções dos profissionais de uma rede intersetorial sobre o atendimento a mulheres em situação de violência. 21(60):51-62. 